\title{
Eigenvalue intervals for iterative systems of nonlinear boundary value problems on time scales
}

\section{Sabbavarapu Nageswara Rao and Allaka Kameswara RaO}

\section{ABSTRACT.}

Values of $\lambda_{1}, \lambda_{2}, \cdots, \lambda_{n}$ are determined for which there exist positive solutions of the iterative system of dynamic equations, $u_{i}^{\Delta \Delta}(t)+$ $\lambda_{i} a_{i}(t) f_{i}\left(u_{i+1}(\sigma(t))\right)=0,1 \leq i \leq n, u_{n+1}(t)=u_{1}(t)$, for $t \in[a, b]_{\mathbb{T}}$, and satisfying the boundary conditions, $\alpha u_{i}(a)-\beta u_{i}^{\Delta}(a)=0=$ $\gamma u_{i}\left(\sigma^{2}(b)\right)+\delta u_{i}^{\Delta}(\sigma(b)), 1 \leq i \leq n$, where $\mathbb{T}$ is a time scale. A Guo-Krasnosel'skii fixed point theorem is applied.

\section{REFERENCES}

[1] Agarwal, R. P. and O'Regan, D., Triple solutions to boundary value problems on time scales, Appl. Math. Lett., 13 (2000), No. 4, 7-11

[2] Agarwal, R. P., O’Regan, D. and Wong, P. J. Y., Positive Solutions of Differential, Difference and Integral Equations, Kluwer Academic, Dordrecht, The Netherlands, 1999

[3] Anderson, D. R., Eigenvalue intervals for a second-order mixed-conditions problem on time scale, Int. J. Nonlinear Diff. Eqns., 7 (2002), 97-104

[4] Anderson, D. R. Eigenvalue intervals for a two-point boundary value problem on a measure chain, J. Comp. Appl. Math., 141 (2002), No. 1-2, 57-64

[5] Bohner, M. and Peterson, A., Dynamic Equations on Time Scales: An Introduction with Applications, Birkhäuser, Boston, Mass, USA, 2001

[6] Benchohra, M., Henderson, J. and Ntouyas, S. K., Eigenvalue problems for systems of nonlinear boundary value problems on time scales, Adv. Difference Equ., 2007 (2007), Article ID 31640

[7] Chyan, C. J., Davis, J. M., Henderson, J. and Yin, W. K. C., Eigenvalue comparisons for differential equations on a measure chain, Elect. J. Diff. Eqns., 1998 (1998), No. 35, 1-7

[8] Chyan, C. J. and Henderson, J., Eigenvalue problems for nonlinear differential equations on a measure chain, J. Math. Anal. Appl., 245 (2000), No. 2, 547-559

[9] Erbe, L. H. and Peterson, A., Positive solutions for a nonlinear differential equation on a measure chain, Math. Comp. Model., 32 (2000), No. 5-6, $571-585$

[10] Erbe, L. H. and Wang, H., On the existence of positive solutions of ordinary differential equations, Proc. Amer. Math. Society., 120 (1994), No. 3 , $743-748$

[11] Graef, J. R. and Yang, B., Boundary value problems for second order nonlinear ordinary differential equations, Comm. Applied Anal., 6 (2002), No. 2, 273-288

[12] Guo, D. J. and Lakshmikantham, V., Nonlinear Problems in Abstract Cones, vol. 5 of Notes and Reports in Mathematics in Science and Engineering, Academic Press, Boston, Mass, USA, 1988

[13] He, Z. Double positive solutions of boundary value problems for p-Laplacian dynamic equations on time scales, Applicable Anal., 84 (2005), No. 4 , 377-390

[14] Kuiper, H. J. On positive solutions of nonlinear elliptic eigenvalue problems, Rend. Circ. Mat. Palermo., 20 (1971), 113-138

[15] Henderson, J. and Wang, H., Positive solutions for nonlinear eigenvalue problems, J. Math. Anal. Appl., 208 (1997), No. 1, 252-259

[16] Henderson, J. and Wang, H., Nonlinear eigenvalue problems for quasilinear systems, Comp. Math. Appl., 49 (2005), No. 11-12, 1941-1949

[17] Henderson, J. and Wang, H., An eigenvalue problem for quasilinear systems, Rocky. Mount. J. Math., 37 (2007), No. 1, 215-228

[18] Hu, L. and Wang, L., Multiple positive solutions of boundary value problems for systems of nonlinear second-order differential equations, J. Math. Anal. Appl., 335 (2007), No. 2, 1052-1060

[19] Infante, G., Eigenvalues of some non-local boundary value problems, Proceedings of the Edinburgh Math. Society., 46 (2003), No. 1, 75-86

[20] Infante, G. and Webb, J. R. L., Loss of positivity in a nonlinear scalar heat equation, Nonlinear Diff. Eqns. Appl., 13 (2006), No. 2, 249-261

[21] Li, W. T. and Sun, H. R., Multiple positive solutions for nonlinear dynamical systems on a measure chain, J. Comp. Appl. Math., 162 (2004), No. 2, 421-430

[22] Ma, R. Y., Multiple nonnegative solutions of second-order systems of boundary value problems, Nonlinear Anal (T. M. A), 42 (2000), No. 6, 1003-1010

[23] Sun, H. R., Existence of positive solutions to second-order time scale systems, Comp. Math. Appl., 49 (2005), No. 1, 131-145

[24] Wang, H., On the number of positive solutions of nonlinear systems, J. Math. Anal. Appl., 281 (2003), No. 1, 287-306

[25] Webb, J. R. L., Positive solutions of some three point boundary value problems via fixed point index theory, Nonlinear Anal (T. M. A), 47 (2001), No. 7, 4319-4332

[26] Zhou, Y. and Xu, Y., Positive solutions of three-point boundary value problems for systems of nonlinear second order ordinary differential equations, J. Math. Anal. Appl., 320 (2006), No. 2, 578-590

DEPARTMENT OF MATHEMATICS

Aditya INSTitute of TeCHNOLOgy AND MANAGEMENT

TEKKALI, 532 201, INDIA

E-mail address: sabbavarapu_nageyahoo.co.in

DEPARTMENT OF MATHEMATICS

Gayatri Vidya PARISHAD COLlEGE OF ENGINEERING FOR WOMEN

MADHURAWADA, VISAKHAPATNAM, 530 048, INDIA

E-mail address: kamesh_1724@yahoo.com 